\title{
Ethics and the Improvising Business
}

\author{
Mark Laver, Ajay Heble, and Tina Piper
}

Musical improvisation represents a profoundly collaborative creative process. The improvised framework demands that musicians collectively and spontaneously negotiate a set of external challenges-possibly including a harmonic progression, a texture, a tempo, a groove, or the expectations of an audience-as well as internal challenges, such as divergent tendencies, tastes, or knowledge bases within the group. A successful negotiation hinges on a dialectic of individual knowledge and collective innovation: musicians depend on the individual years of practice through which they developed their unique technical, listening, and expressive skills, while at the same time responding quickly and spontaneously to the rest of the group (and to other variables in the performance milieu) in a manner that evinces innovation, creativity, and surprise. Therefore, while improvisation depends heavily on a musician's cultivation of individual skills, both the improvised process and the (hopefully successful) outcome of that process are equally shared among members of the group.

In light of the collaborative essence of musical creativity, a growing number of management theorists are looking to group musical improvisation as a model for corporate design. In the post-Fordist global marketplace, sudden change has become a quotidian part of the business experience. Just as a group of improvisers must negotiate sudden musical changes, unanticipated changes in the marketplace demand a similar kind of collaborative response. Faced with the unexpected, many businesses respond with collective flexibility. They establish a profoundly dialogical management structure, encouraging employees at all levels to engage in problem-solving. Akin to the musical knowledge-innovation dialectic, businesses walk the line between what Roger Martin calls reliability and validity (Leavy 23), ${ }^{1}$ trusting in the knowledge and study that underlies their extant systems and models, while at the same time embracing the promise held by innovation, creativity, and surprise. Above all, they work to engage every individual in the group, giving every employee a sense of collective ownership over the challenges and the solutions.

While this burgeoning area in management studies has focused on the ways in which improvised musical practice might serve as a model for fomenting collective creativity in a corporate environment, very little scholarship to date has addressed this area of study in the context of the sociopolitical ethics that are so often an intrinsic element of improvised musicking. Because of the putatively intense dialogism and egalitarianism demanded of improvising musicians, scholars of music and culture, as well as musicians have identified the improvised performance paradigm as a potentially deeply ethical framework for music making. As Daniel Fischlin and Ajay Heble note, for instance, in their Introduction to The Other Side of Nowhere: Jazz, Improvisation, and Communities in Dialogue, there is "an identifiable and radical form of improvisational practices in which concepts of alternative community formation, social activism, rehistoricization of minoritized cultures, and critical modes of resistance and dialogue are in evidence" (2). Indeed, in light of recent global political and economic developments-including the fallout from the ethically vexed speculative investing that led to the dotcom crash of 2000 , the 2008 mortgage crisis, the increasing visibility of ethical activism in the consumer base, ${ }^{2}$ and the rise of the Occupy movements in 2011 -ethical concerns have become increasingly urgent for corporations of virtually all stripes. These and countless other events have forced corporations to consider the sociocultural, political, and environmental impact of their actions, and to begin to reimagine business policy in terms of social policy-a transition often framed within the discursive rubric of Corporate Social

Responsibility (CSR). Indeed, a growing number of political power-brokers such as former UN Secretary General Kofi Annan and Davos World Economic Forum founder and executive Chair Klaus Schwab have called on businesses to recognize the emergent ethical obligations that their pervasive influence entails (Adler 209). This move has been complicated by a reverse trend, as Non-Governmental Organizations and other non-profit groups increasingly reconceptualize social policy in business terms, adopting innovative business models and fundraising strategies. The boundaries between business, activism, and ethical engagement are blurring as methods and practices are exchanged and transformed by these hybrid organizations. With this in mind, the communitarian ethics, social activism, and contra-capitalist critiques that attend to improvised musics around the world are every bit as relevant to management studies as the collaborative modes of creativity that undergird improvisatory praxis.

At the same time, however, it is crucial to keep in mind that improvised musics frequently emerge from marginalized communities around the world. Even where comparatively affluent communities practice the music, it is commonly inextricable from contra-capitalist politics. Improvisation therefore often represents a means of sounding resistancea kind of "musicking from below" that challenges the logics of the free market economy by purposefully severing aesthetic value from exchange value: from the scope of production and the degree of consumption. In such a context, a corporate use of improvisation as a model for creative problem-solving that ignores the music's indelible sociopolitical ethic stands as a clear example of hegemonic appropriation and dilution of a provocative, subaltern cultural practice. By the same token, a corporate use of the music that pays lip service to the improvisational ethic in order to obfuscate unethical behaviour in other areas-_greenwashing," for instance, or dedicating a meager proportion of net profit to CSR initiatives in order to achieve marketing goals-constitutes dissimulation at best; at 
worst, hypocrisy. What happens, then, when the trust, dialogue, and collaboration that many cultural theorists and musicians have associated with improvised musical practices get repurposed as prongs in corporate marketing strategies, when industry leaders are taught by theorists of management to use improvisation as a way of building team spirit in order to boost profits? What happens, that is, when improvisation gets reduced to a method and framed as part of the logic and priorities of corporate accumulation, rather than as a musical practice with, as noted above, historical links to concepts of alternative community formation, human rights, and social activism?

This special topics issue of Critical Studies in Improvisation / Études critiques en improvisation grows out of "Making the Changes: Ethics and the Improvising Business," a symposium hosted at the University of Guelph by the Improvisation, Community, and Social Practice (ICASP) project in December 2011 that brought together leaders in the fields of cultural studies, management, ethnomusicology, business ethics, music performance, education, and human rights. The guiding questions of that symposium have become the central themes addressed in this issue: What does musical improvisation have to offer as a management model for corporations and not-for-profit organizations? What is the relationship between improvisation and creativity in the global marketplace? How might an improvised ethical framework translate in a for-profit corporate environment, and what are the sociopolitical implications of that translation? How can improvised praxis and ethics impact Corporate Social Responsibility projects? In what ways are improvisatory ethics manifest in the emergent discourses and practices associated with social innovation? Is it possible for a large corporation to honestly acknowledge and respond to improvising musicians' socioeconomic critiques while continuing to operate within an expansionist, capitalist economic framework? What is at stake when large corporations adopt (or co-opt) musical practices-particularly those associated with subaltern communities?

The structure of this issue also mirrors the structure of the 2011 event. While every participant in the symposium was committed to rethinking management practices and corporate priorities with a view to the corporation's emerging role as an agent of social policy under neoliberal capitalism, the speakers frequently disagreed about the position of capitalism itself in the discussion. Are ethical considerations best addressed pragmatically within the existing capitalist socioeconomic framework, or can a meaningful conversation about ethics and Corporate Citizenship only begin with a wholesale deconstruction of capitalism itself, particularly in its twenty-first-century, neoliberal incarnation? This fundamental disagreement led to a productive tension between representatives of the various fields of study-a kind of "antagonistic cooperation," as Ralph Ellison might have it. We have endeavoured to reflect that fruitful antinomy in this issue by including articles, interviews, and opinion pieces that represent a similarly rich variety of perspectives. Chris MacDonald's thoughtful discussion of the utility of the improvisation metaphor for the negotiation of corporate ethical crisis is paired with Scott Thomson's scathing critique of the deleterious impact of capitalism writ large on non-commercial improvised musicking. In adjacent interviews, Keith Sawyer argues for improvisation's ability to act as a socially and ethically redemptive force within the existing corporate-capitalist paradigm, while Joel Bakan counters that corporations are inherently psychopathic and should have their improvisatory capacities severely delimited by a dramatically more robust state regulatory framework. Nick Sorensen's thorough critical examination of the extant literature on improvisation and management appears alongside Peter Johnston's analysis of the ontological contradiction between the capitalist profit imperative and the "democratic, egalitarian aims of those who identify as improvisers" (Johnston, this issue) and Mark Laver's proposal that the improvisation metaphor affords a deceptively aesthetic gloss to neoliberal socioeconomic policy, obscuring the cataclysmic human and ecological impact of neoliberalism on a global scale. Rounding out this issue of Critical Studies in Improvisation / Études critiques en improvisation are two general topics articles, both focused, at least in part, on the music of the Grateful Dead. Michael Kaler looks at the Dead's use of blues and soul songs to discuss the importance of blues-related styles for the development of rock improvisation, while Melvin Backstrom, via both the Dead and Sun Ra, uses Pierre Bourdieu's discussion of the field of cultural production to think through some of the limits of freedom in improvisationally-based musical practices.

\section{Acknowledgements}

We acknowledge and extend our warm thanks to the CSI/ECI team: Managing Editor Michelle Peek; copyeditors and proofreaders Leslie Allin, Greg Fenton, David Lee, and Mark Kaethler; book reviews editor Rob Wallace; and Wayne Johnston and his staff at the University of Guelph Library for their ongoing support. Special thanks to Cheldon Paterson (aka SlowPitch) for permitting us to use his piece, "Mind Ctrl," as the audio for the issue splash page. Thanks also to Dr. Charles Limb for the splash page photograph. All contributions to the special topics focus for this issue were edited by Mark Laver, Ajay Heble, and Tina Piper. The two general topics essays were edited by our regular in-house editors, Frederique Arroyas, Daniel Fischlin, and Ajay Heble. 
Notes

${ }^{1}$ See Roger Martin's The Opposable Mind: Winning Through Integrative Thinking. (Harvard Business Press, 2009.)

${ }^{2}$ Consider, for example, the rise of social responsible investing (mutual funds that aim to eschew ethically vexed investments like the tobacco industry or weapons manufacturers), or growing consumer consciousness about animal welfare in both the agricultural sector and the pharmaceutical and cosmetics industries.

\section{Works Cited}

Adler, Nancy. "Leading Beautifully: The Creative Economy and Beyond." Journal of Management Inquiry 20.3 (2011): 208-221. Print.

Fischlin, Daniel and Ajay Heble. "The Other Side of Nowhere: Jazz, Improvisation, and Communities in Dialogue." The Other Side of Nowhere: Jazz, Improvisation, and Communities in Dialogue. Ed. Daniel Fischlin and Ajay Heble. Middletown: Wesleyan UP, 2004. 1-42. Print.

Leavy, Brian. "Roger Martin explores three big ideas: customer capitalism, integrative thinking and design thinking." Strategy \& Leadership 39 (2011): 19-26. Print. 